\title{
Modeling and vulnerability of historical city centers in seismic areas: a case study in Lisbon
}

\author{
Luis F. Ramos, Paulo B. Lourenço* \\ Department of Civil Engineering, University of Minho, Azurém, 4800-058 Guimarães, Portugal
}

Received 1 April 2003; received in revised form 6 February 2004; accepted 13 April 2004

\begin{abstract}
Historical city buildings are an integral part of the built heritage to be preserved, and their safety is a primary requirement in seismic areas. Collapse of ancient masonry buildings due to seismic actions occur mostly due to overturning of the perimeter walls. This paper addresses the issue of seismic analysis and vulnerability of historical city centers, with a specific case study: the 18th century downtown part of Lisbon, Portugal. The finite element method was adopted for a number of different analyses, introducing non-linear behavior of the materials. From the analysis, the following issues have been addressed: (a) seismic vulnerability of this type of constructions; (b) influence of the group of buildings on the seismic behavior of the individual buildings that compose a single compound; and (c) methodology for action. It is believed that the conclusions obtained with respect to the seismic assessment of masonry buildings can be extrapolated for the wide variety of historical city centers.
\end{abstract}

(C) 2004 Elsevier Ltd. All rights reserved.

Keywords: Non-linear analysis; Cracking; Seismic analysis; Seismic vulnerability; Historical masonry constructions

\section{Introduction}

Today, it is certain that historical city buildings are an integral part of the built heritage to be preserved. The urban fabric of historical city centers, in terms of their construction, reveals considerable differences according to the geographical, cultural and technical backgrounds. The differences result in buildings with typical local characteristics and authenticity, which are the most important reasons for conservation work. The approaches towards preservation have evolved in the last decades, e.g. [1], but a primary requirement must be safety, which is critical in seismic areas.

In spite of the diversity referred above, a common matrix can usually be established for the seismic areas, more structural than technological. This consists of low building height (up to three stories), moderate spans (maximum of 4 or $5 \mathrm{~m}$ ) and large thickness of the walls (less than one-seventh of the height) [2]. Together with

\footnotetext{
* Corresponding author. Tel.: +351-253-510-200; fax: +351-253510-217.

E-mail address: pbl@civil.uminho.pt (P.B. Lourenço).
}

these general characteristics, common to the structure of most old masonry buildings, the high vulnerability of historical masonry buildings to seismic actions is mostly due to the absence of adequate connections between the various parts (masonry walls, wooden beams in the floors and wooden beams in the roof). This characteristic leads to overturning collapse of the perimeter walls under seismic horizontal acceleration. Simplified limit analysis methods are often used for safety analysis and design of strengthening [3-5].

The conservation of historical city centers in seismic areas requires, thus, a strategic plan and proper methodology including aspects such as: Phase 1 -preliminary investigation, interpretation of historical documentation and understanding the historical context, and appraisal of the general structural characteristics of the construction; Phase 2-full diagnosis, making use of selected non-destructive testing and numerical analyses; Phase 3-designing of structural modifications, according to the requirements of safety, upgrading, compatibility and durability, as well as the modern principles of action in the built heritage such as reversibility, unobtrusiveness and minimum 
modification; Phase 4 carrying out the works with proper quality assurance and qualified workers; Phase 5-monitoring, as an evaluation of the effects associated with the modifications. The approach of combining conservation requirements with safety, within the restoration of historical city centers, has spread swiftly in Italy, thanks to the work of Giuffrè, e.g. $[3,6]$. The proposed "codes of practice" for different historical cities contain all available informations on local seismic activity, original construction techniques and precarious situations, suggesting methods of validation of the proposed structural modifications and helping those responsible for planning the actual site works to select adequate and efficient techniques, which respect the local culture and limit future damage.

Nevertheless, the usefulness of the damage revealed through actual earthquake experience must be stressed. The evidence of observed past damage constitutes significant cultural background for designers, without being summarized in inexpressive figures or being reduced to flat parameters. Clearly, this information must be completed by the modern physical parameters available to register seismic activity, both in terms of ground acceleration and instrumental monitoring of case studies. However, it is noted that even with proper consideration of the lessons learned from earthquakes, the problems of repairing and retrofitting masonry buildings in historical centers remains a true challenge, see e.g. [7].

The present paper focus solely on Phase 2 referred above, namely in the aspects of numerical modeling applied to the 18th century historical center of Lisbon, as a case study. The buildings of the "Pombaline" area in Lisbon, totally rebuilt after the earthquake of 1755 and named after the Marquis of Pombal, possess a high cultural value as witnesses of novel construction techniques, novel functional requirements and 18th century large scale city planning, with very few similar situations in the world.

The Pombaline buildings have not yet suffered the effect of a moderate or strong earthquake, meaning that there is no expertise on their actual behavior under seismic actions. The state of structural conservation of the buildings is not well known, being the main reason for carrying out the present vulnerability study. For this purpose, it was decided to select a building compound near the famous square on downtown Lisbon, Praça do Comércio (Commerce Square). The compound has been analyzed using non-linear finite elements, in order to assess its stability with respect to overturning mechanisms.

\section{The historic survey of Pombaline buildings}

The "Baixa Pombalina" in Lisbon, the historical downtown area rebuilt after the disastrous 1755 earthquake, is composed of approximately 60 blocks, most of them rectangular and consisting of an average of seven buildings. Within each block, the buildings are constructed side by side, sharing the same gable walls. The soil is very soft and of alluvial nature, resulting in a local amplification of the seismic action, namely for frequencies in the range of $4-6 \mathrm{~Hz}$ [8]. As a result, the area was totally destroyed in 1755 , which is a $\mathrm{X}$ degree scenario in the MKS macro-seismic scale.

The Pombaline buildings are grouped in rectangular blocks or compounds, measuring around $70.0 \times 25.0 \mathrm{~m}^{2}$ in plan, with a narrow central yard measuring $45.0 \times 2.0 \mathrm{~m}^{2}$. The buildings had originally five floors (including ground floor and attic, see Fig. 1) and the constant height of the facade was approximately equal to the width of the main streets.

The original concept of Pombaline buildings aimed at providing strength to horizontal loading and capacity to dissipate energy. Among the features of the construction system, the so-called "gaiola", i.e. cage, stands out, see Fig. 1a. The cage consists of a set of oak or holm-oak timber members embedded along the inner face of the main stone masonry facade walls, see Fig. 1b. Then, ashlars placed around the door and window openings are tied against this internal timber grid, by means of iron cross ties (A). Additional bracing is provided by the timber floors, which originally possessed some diaphragm action enhanced by iron ties (B), bolted to the floor beams and deeply embedded in masonry main walls, and by timber connectors, named "mãos", i.e. hands $(\mathrm{C})$, nailed to the above mentioned timber grid and also embedded in the masonry. The confined facade piers are then connected to a bi-directional vertical bracing system of timber-framed walls, with light ceramic and rubble masonry infill. The term "gaiola" was coined because the building seemed like a big cage, with the carpentry work high up in the air, generally some floors ahead of the masons.

The buildings are usually supported on a timber grid laid on short timber piles, intended only to stiffen the alluvial soil and to create a working platform above the water level. In many places, where the new buildings are constructed on top of the remains of pre-earthquake buildings (street slabs, footings, masonry blocks, etc.), the ancient constructions were used as foundations.

The whole ground floor structure was built in stone masonry. Besides the external walls, it was possible to find barrel vaults, carefully laid in dry stone masonry, or crossed vaults, made from clay brick masonry. Walls, arches or columns in dry stone masonry support these vaults. This system provides large stiffness to the structure in its base and stops fire propagation from 
(a)

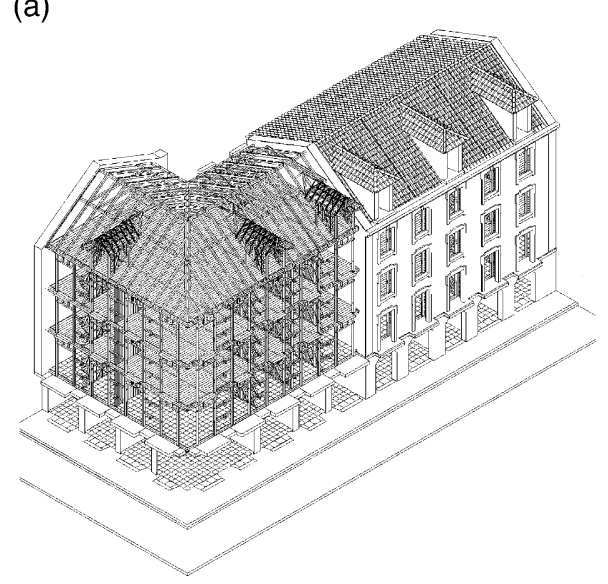

(b)

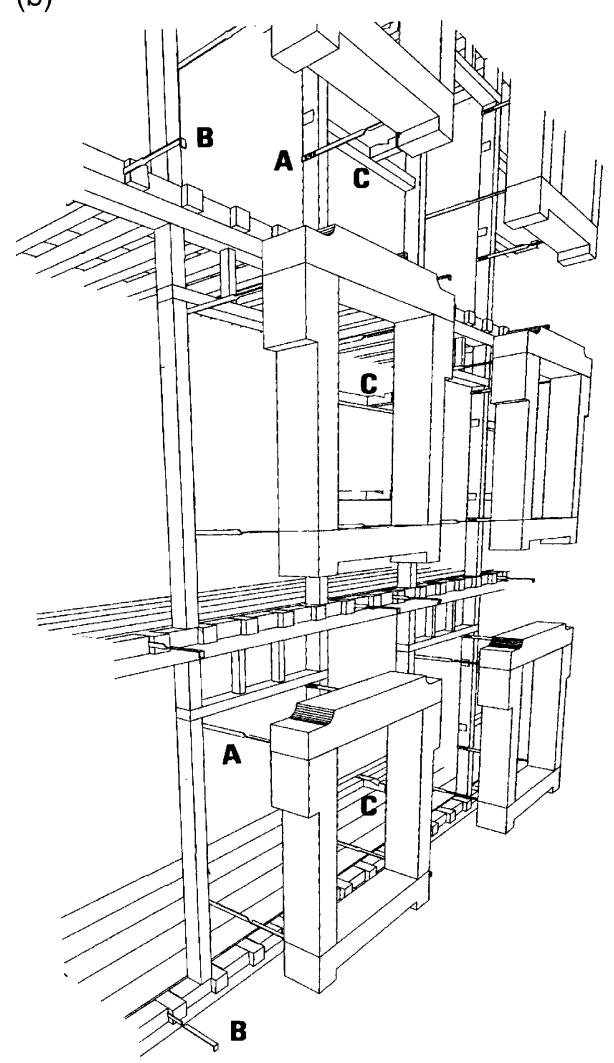

Fig. 1. Aspects of the Pombaline construction: (a) building with the façade walls removed to show the timber bracing system; and (b) detail of the timber frame and anchoring system to the main façade pilasters).

the retail area (ground floor) to the rest of the building. The infill of the vaults was recycled from the ruins of the earthquake of 1755 .

The external walls of the buildings are made of stone masonry, using limestone units and lime mortar joints. These walls are connected to the internal stiffening timber structure referred above. The typical thickness of the external walls is $0.90 \mathrm{~m}$, in the ground floor, with decreasing thickness through the elevation of the build- ing. Additionally, internal masonry walls, perpendicular to the external walls and with a thickness of about $0.50 \mathrm{~m}$, could be found. These internal walls were built from the ground floor up to and beyond the roofs, without any opening. Such stone masonry walls had the purpose of dividing the buildings and, again, preventing fire propagation.

The "gaiola" system is considered an innovation of the Pombaline city planning and is a result of property expropriation. The buildings needed to have five floors and not three as initially planned (low buildings resist better to earthquakes than tall buildings). It is accepted today that most of the constructive details of the new structural system were produced by the master draftsmen of Casa do Risco (Draughtsman House), with experience in the design of timber structures for ships. These details were probably handed down to the building carpenters orally, or by means of drawings and sketches presently lost. Even if many references exist to a possible code that would assist and define member sizes, connection details and constructive procedures, no document has been found specifying the "gaiola" construction or establishing its mandatory character.

The earthquake of 1783, in Calabria, Italy, appears in the literature as having originated the first rules for anti-seismic construction, adopting timber-framed walls with mortared stone infill, instead of rubble. However, the concept seems to have been inspired on the Pombaline constructive system, as recognized in Ref. [9].

Unfortunately, some of the buildings in Lisbon have suffered severe structural modifications, particularly after the onset of reinforced concrete. The main changes undergone by the buildings in "Baixa Pombalina" are: (a) construction of extra floors; (b) enlargement of existing facade openings and removal of walls and pillars, notably on the ground floor; and (c) addition of steel and reinforced concrete elements.

\subsection{Description of the compound selected for seismic vulnerability study}

For the assessment of the seismic vulnerability of the Pombaline construction, a building compound near the famous square on downtown Lisbon, Praça do Comércio (Commerce Square), was selected. The reason for selecting this compound was that substantial geometrical data and information about the building materials were already available. The compound is located between the streets of Prata (Silver), Comércio (Commerce), Fanqueiros (Drapers) and Alfândega (Custom-House). The compound is known as the Martinho da Arcada block, named after a well-known café.

The selected block is facing Praça do Comércio and has a considerably large size, with in plan size of $62.5 \times 43.5 \mathrm{~m}^{2}$. The height of the individual buildings 
ranges from 18.0 to $25.0 \mathrm{~m}$. After an initial request by the General Directorate for National Buildings and Monuments for a rather detailed survey in one of the buildings, the full block was surveyed, although in less detail [10].

The structural survey of this particular block indicated that about $50 \%$ of the original structural system was severely modified and only $20 \%$ of the structural system was in its original configuration. In particular, a reinforced concrete framed structure had been inserted in one of the buildings and several reinforced concrete and composite steel-concrete slabs replaced the original timber floors. Here, it must be stated that experience has demonstrated that the large mass associated with these structural elements usually results in premature collapse of the masonry external walls [11].

\section{Numerical analysis of the selected compound}

\subsection{Considerations on geometry and loading}

The finite element method was adopted for carrying out all numerical calculations, using the package DIANA $^{\circledR}$ [12]. The geometry adopted in the models has been simplified to a great extent because the response of the actual construction depends significantly on the behavior of timber connections and ties. On the one hand, it is likely that the ties and nails are partly corroded and, on the other hand, the mechanical characterization of such semi-rigid connections is rather difficult and requires destructive testing. Therefore, the analyses to be carried out should be considered as a best guess, at the present stage of knowledge, which is likely to reproduce the global behavior and overturning mechanisms but cannot reproduce local failures at the connections between various structural elements.

The loads considered in the analysis were the vertical actions (self-weight and live load) and the seismic action. The seismic action was introduced by the application of a set of equivalent horizontal loads proportional to the weight of the structure. The reason for this assumption is that the static analysis method can be easily coupled with non-linear material behavior. The non-linear analyses were carried out with indirect displacement control (arc-length method) with line searches, using a full Newton-Raphson solving technique.

Here, it is noted that the reference method for determining the seismic effects for new constructions is the modal response analysis, using a linear elastic model of the structure [13]. Linear elastic analysis, based on the theory of elasticity, has widely been used for the verification of both ultimate and serviceability limit states of, e.g., reinforced concrete structures. But, for serviceability limit states, a gradual evolution of cracking should be considered and, for ultimate limit states, careful detailing of the reinforcement to cover all zones where tensile stresses may appear is required. As stressed in Ref. [14], consideration of linear elastic behavior for historical masonry structures is, in general, not recommended. A powerful alternative to modal response analysis is the non-linear time history analysis. The difficulty in using direct integration of the differential equations of motion, using base accelerograms, is that the time requirements render most analyses non-feasible. It is noticed that a dynamic analysis requires a minimum of five different accelerograms, multiplied by two different seismic actions, multiplied by two orthogonal directions. This results in 20 different analyses, without considering the horizontal components of the seismic action acting simultaneously and the vertical component of the seismic action.

As suggested by Parts 1-4 of Eurocode 8 [13], for existing structures, it seems more appropriate to carry out the analysis using approximate static non-linear methods. In the static methods, the seismic effect is defined by the base shear coefficient, coined as seismic coefficient, which defines the percentage of the total weight of the building that must be considered as a horizontal force, also total, applied to the structure. This procedure ignores additional torsional effects, meaning that the value of the seismic coefficient must be conservative. For modern buildings, existing codes adopt detailed procedures to calculate the seismic coefficient applicable for each case, as a function of the seismic zone, soil type, fundamental frequency of vibration for the structure and the available ductility and damping. These procedures have been extensively calibrated against results obtained by the general methods, but historical buildings possess characteristics considerably different from the ones used to calibrate the codes. For areas of significant seismic risk, the seismic coefficient can be assumed to vary between 0.1 and 0.3 [15]. For Lisbon, the Portuguese code of practice defines a value of 0.22 [16].

\subsection{Adopted material properties}

The elastic properties have been obtained from experimental data [10], resulting in a Young modulus of 1000 and $50 \mathrm{~N} / \mathrm{mm}^{2}$, for the external walls and for the internal walls, respectively. The Young modulus of timber and concrete were assumed equal to 10000 and $30000 \mathrm{~N} / \mathrm{mm}^{2}$, respectively. The Poisson coefficient for all materials was assumed equal to 0.2 .

Three specimens were removed for testing from a gable masonry wall. The specimens had average dimensions of $0.70 \times 0.75 \times 1.40 \mathrm{~m}^{3}$ and were tested under uniaxial compression, see Fig. 2. The response is very 
(a)

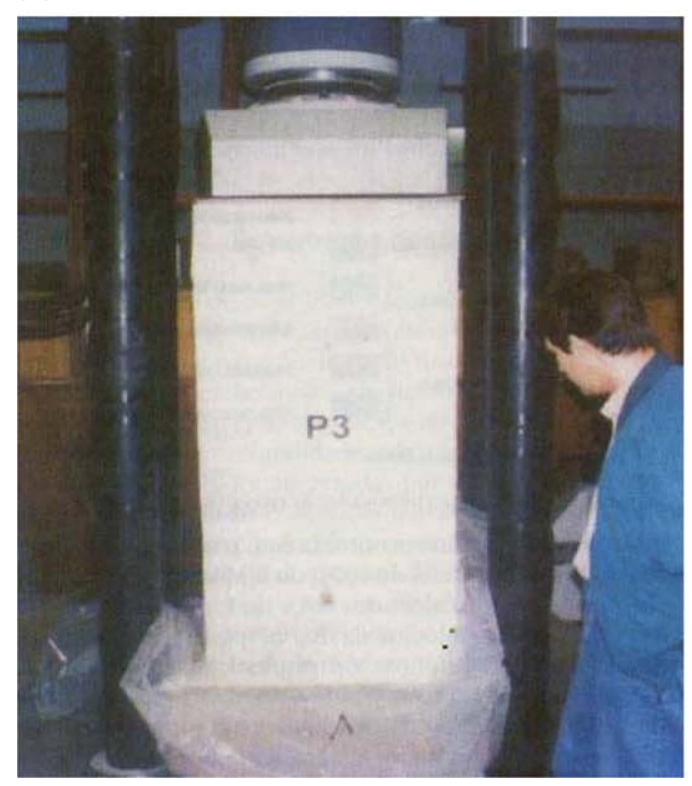

(b)

\section{Stress $\left(\mathrm{N} / \mathrm{mm}^{2}\right)$}

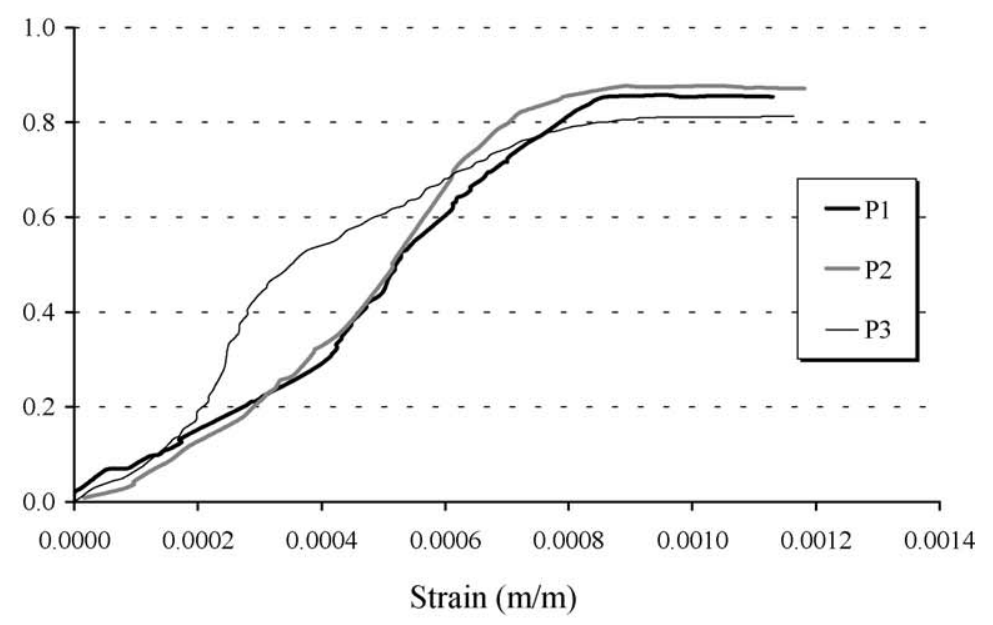

Fig. 2. Mechanical characterization of the external walls under uniaxial compressive loading (three specimens): (a) typical aspect of the specimens; and (b) obtained stress-strain diagrams.

ductile with an average uniaxial compressive strength of $0.85 \mathrm{~N} / \mathrm{mm}^{2}$.

For the internal walls, three specimens were also removed for testing. The specimens had average dimensions of $2.58 \times 3.46 \times 0.21 \mathrm{~m}^{3}$, and were tested under combined constant vertical loading and cyclic horizontal loading (as shear walls), see Fig. 3. The response is again very ductile and features enormous energy capacity deformation, even if the stiffness and strength are rather low.

The possibility of occurrence of non-linear behavior in the model was limited to cracking of masonry, because the features to be studied are overturning mechanisms and separation between structural elements due to insufficient connection. The adopted model is based on a traditional smeared crack model, specified as a combination of tension cut-off (two orthogonal cracks in each principal stress plane $\sigma_{1}-\sigma_{2}$, $\sigma_{2}-\sigma_{3}$ and $\sigma_{1}-\sigma_{3}$ ), tension softening and shear retention, the reader being referred to Ref. [17] for further reading. In the present work, a zero tensile strength was adopted, which is a conservative approach, extensively used for historical masonry constructions. Specific formulations for such a "no-tension model" have been studied by different authors, e.g. [18], but any softening model is able to reproduce no-tension models. More sophisticated models can be used, e.g. [19], but additional testing would be required to find the necessary data.

\subsection{Evaluation of the contribution of the internal walls in Pombaline buildings}

Given the structural complexity of the buildings, in terms of geometry and load-bearing elements, and the large size of the compound, it was decided to analyze a simpler model first. This preliminary model and analysis of an isolated typical "Pombaline" building is used for the purpose of discussing the combined seismic behavior of the external masonry walls and internal composite walls. In such a way, this analysis allows to define a modeling strategy for the large compound, namely with respect to the inclusion of the low stiffness internal transverse walls.

The isolated Pombaline building adopted for the analysis has a prismatic shape, with an in plan size of $13.0 \times 15.0 \mathrm{~m}^{2}$ and a height of $8.2 \mathrm{~m}$, corresponding to two floors. The thickness of the walls is 0.70 and 0.20 $\mathrm{m}$, for the external and internal walls, respectively. The timber beams that constitute the floor, every $1.5 \mathrm{~m}$, have a cross-section of $0.08 \times 0.14 \mathrm{~m}^{2}$. Non-linear behavior was adopted for all elements, with the exception of the timber beams that were assumed to remain linear elastic throughout the analysis. Perfect connection was assumed between all elements, namely between timber floors and masonry walls, and between external and internal masonry walls. Nevertheless, separation due to cracking is possible to occur at the connections.

Two numeric models of a typical building were prepared, one model with an internal wall and floor, and 
(a)

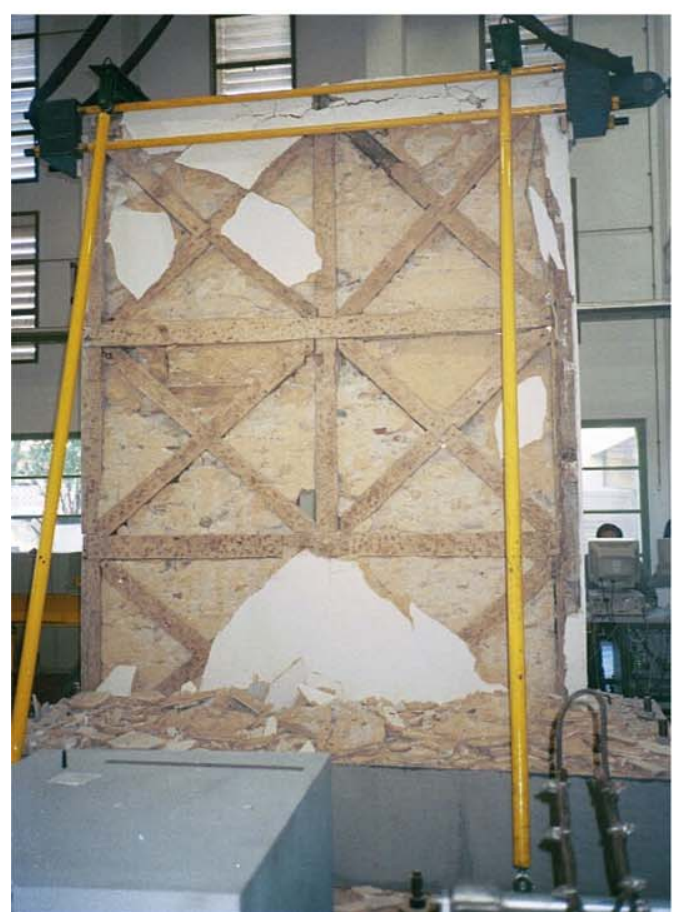

(b)

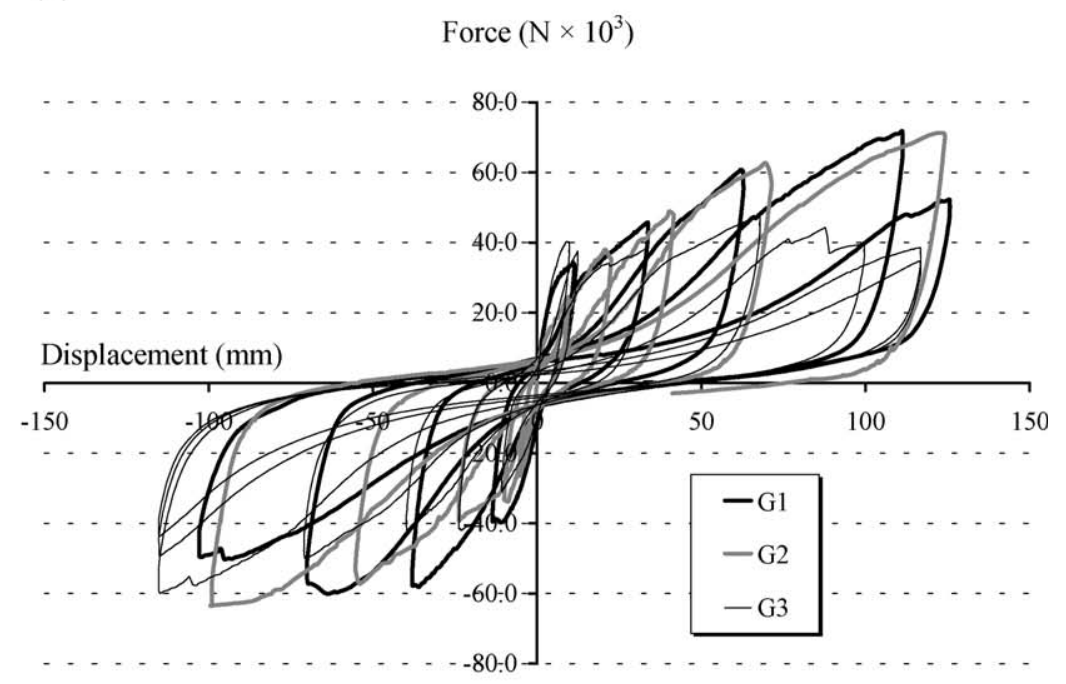

Fig. 3. Mechanical characterization of the internal walls under combined in-plane vertical and horizontal loading (three specimens): (a) typical aspect of the specimens; and (b) obtained horizontal force-displacement diagrams.

another model without the internal wall and floor. Three-dimensional quadratic volume elements were used for the walls (two elements through the thickness of the walls, with an average size of $0.5 \mathrm{~m}$ ), while threedimensional linear beam elements were used to model the timber floor. Fig. 4 shows the results of the analysis for the seismic load combination required by the Portuguese code, in terms of cracking patterns (maximum principal strains) and deformed meshes, for seismic loading parallel to the internal walls.

The results obtained in this preliminary analysis allowed concluding that [10]:

- Collapse mechanisms in the masonry walls were associated to out-of-plane failure;

- The base reaction of the internal wall is just $10 \%$ of the total shear force, when the seismic acts along the (a)

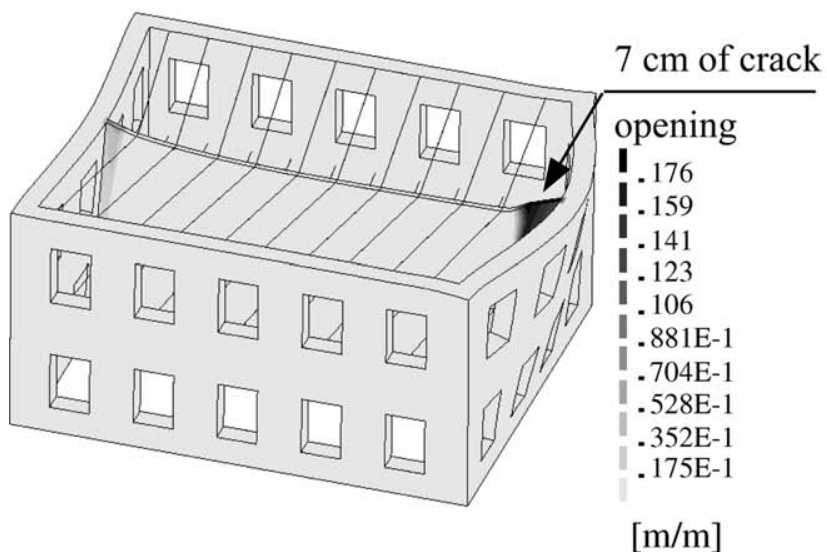

(b)

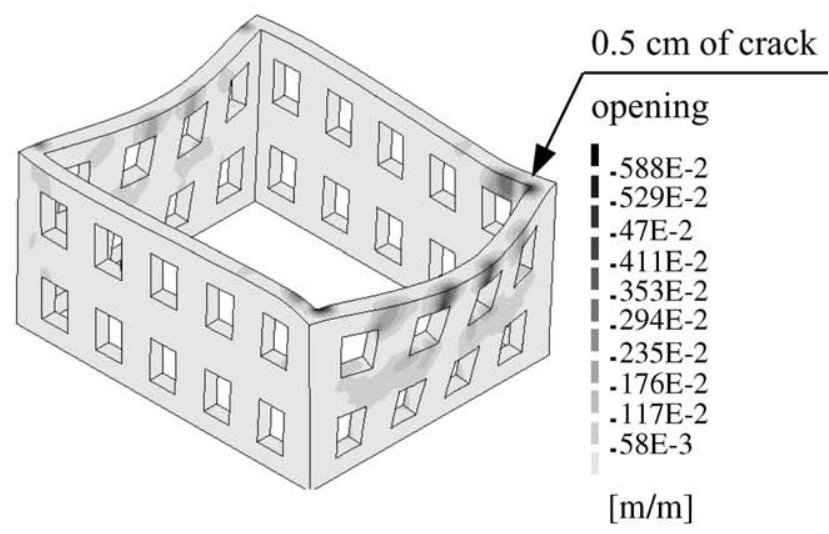

Fig. 4. Cracking pattern and deformed mesh for preliminary analysis: (a) model with internal wall and timber floor; and (b) model without internal wall and timber floor (contour of maximum principal strains). 
direction of the internal walls. When the seismic action acts perpendicular to the internal walls, the contribution of the internal wall to the global strength is negligible;

- The internal walls separate from the external masonry walls at a very early stage of loading, contributing to the increase of damage in the building;

- In the study of the seismic vulnerabilities of this type of structures, modeling the building without the internal walls and timber floors is conservative.

As stated before, the effectiveness of the timber connections after 250 years must be questioned due to high moisture contents, particularly in the vicinity of the external walls. For the compound to be studied in the present paper, the structural survey indicated that most of the internal walls have been removed due to questionable modifications. Therefore, for the full analysis of the compound, internal walls and timber floors have not been included in the model, being replaced by equivalent static loads.

\subsection{Adopted model for the selected compound}

The finite element model for the compound included quadratic shell elements, to represent the reinforced concrete slabs, the composite slabs and masonry vaults in the ground level, and quadratic volume elements, to represent masonry walls (one element through the thickness of the walls, with an average size of $0.5 \mathrm{~m}$ ), masonry arches and stone vaults in the arcades as well as reinforced concrete columns, see Fig. 5. The internal composite walls, the timber floors and the timber roofs were not considered in the analysis, as discussed above. However, the loads associated with these elements were included in the model, as additional static loads. This hypothesis is questionable and it is not acceptable to carry out heavy structural modifications of the buildings, taking into account the need to preserve the authenticity value of this heritage.

All the degrees of freedom of the nodes belonging to the cross-section at the base of the buildings were fully restrained. Such model assumption is normal for linear elastic analysis of modern buildings with adequate footings. In the present case, the existence of high bending moments at the foundation is not possible, due to the material non-linear behavior adopted for the masonry walls.

As stressed before, all elements are connected together and the timber elements are not considered in the model, being the inner timber grid, the timber floor, the internal composite walls and the corresponding iron ties neglected. This option is justifiable from a designer perspective at this stage of knowledge, because it is expected that the behavior of the timber elements, nails and iron ties is heavily deteriorated after 250 years.

The full model is rather complex from the geometrical and material points of view, comprising 8820 elements with 57267 nodes, totaling approximately 160000 degrees of freedom. Five loading combinations were applied: one corresponding to the prescribed vertical loads, and four load combinations for horizontal actions, associated with the seismic action acting along the main directions of the compound. Six man-months were required for creating the mesh and performing the five non-linear analyses.

Non-linear behavior was adopted for all elements, with the exception of the concrete and composite slabs that were assumed linear elastic throughout the analysis. In fact, the slabs were considered in the model only to simplify the definition of loads and to introduce a rigid diaphragmatic effect for the seismic analysis.

\subsection{Results for vertical loading \\ $(1.5 \times$ dead load $+1.5 \times$ live load $)$}

The minimum principal (compressive) stresses obtained in the analysis for the case of vertical loads are illustrated in Fig. 6. Here, it is noted that compression is negative as usually adopted in finite element analysis. The average value of the compressive stresses at the base of the buildings is around $0.5 \mathrm{~N} / \mathrm{mm}^{2}$, but stress peaks of $1.5 \mathrm{~N} / \mathrm{mm}^{2}$ can be encountered, namely in masonry columns. Such peaks can be considered acceptable as it is expected that the columns are made of good quality masonry. In the areas where reinforced concrete columns exist, the stress peaks reach $5.7 \mathrm{~N} /$ $\mathrm{mm}^{2}$, which is a notably high value in comparison with the average stresses in the masonry walls. On the other hand, cracking is rather limited at this ultimate limit state, being more severe at the vaults in the base of building $\mathrm{A}$, with a maximum crack width of $0.3 \mathrm{~mm}$.

Therefore, it seems that structural changes (introduction of structural elements with stiffness and weight very different from the original construction, and removal of the composite internal walls) did not affect significantly the structural performance of the block with respect to vertical loading.

\subsection{Results for seismic loading $(1.0 \times$ dead load + $0.2 \times$ live load $+S F \times$ earthquake load)}

In relation to the seismic behavior, it should be expected that the removal of the composite internal walls affects the safety of the construction. The external walls must resist all the horizontal actions and the lack of bracing will result in premature collapse of the structure.

Figs. 7 and 8 show the damage of the walls in terms of cracking patterns (maximum principal strains) and 


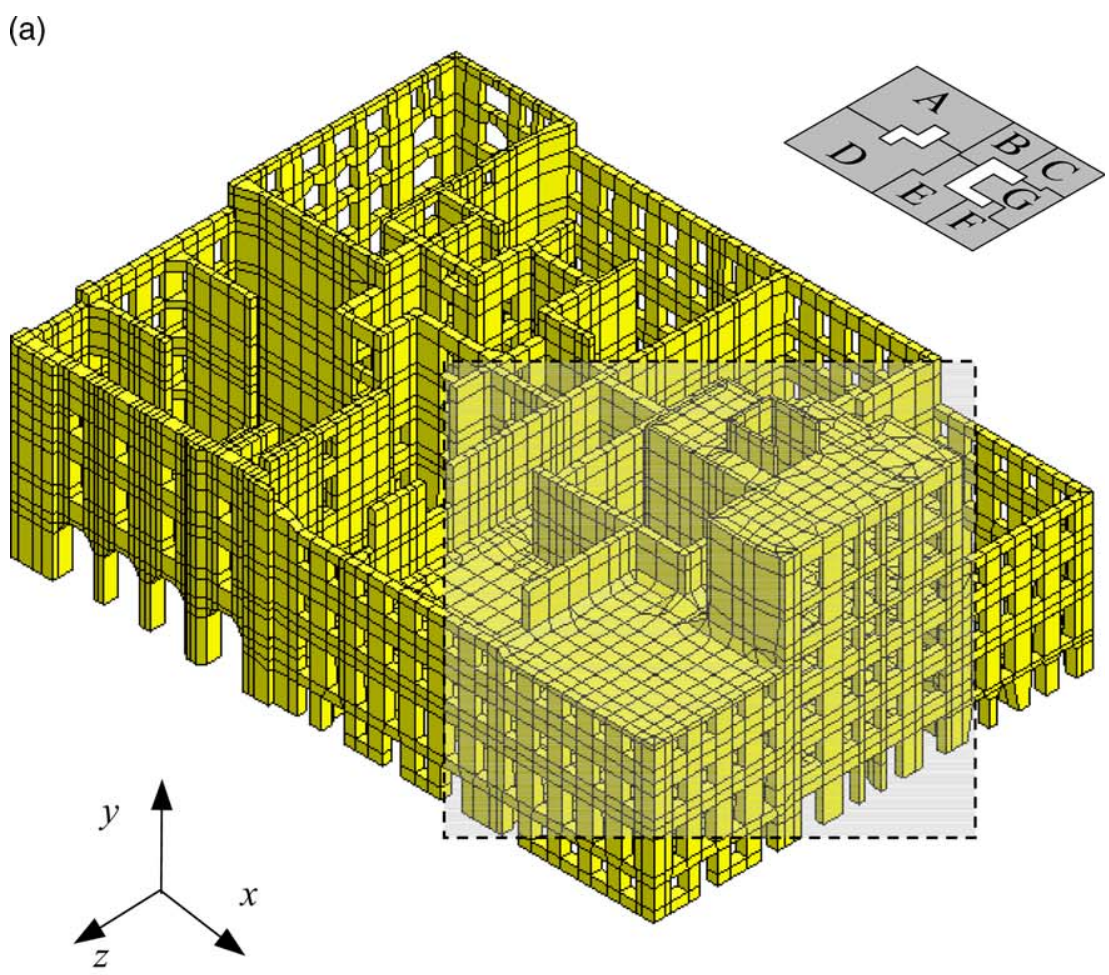

(b)

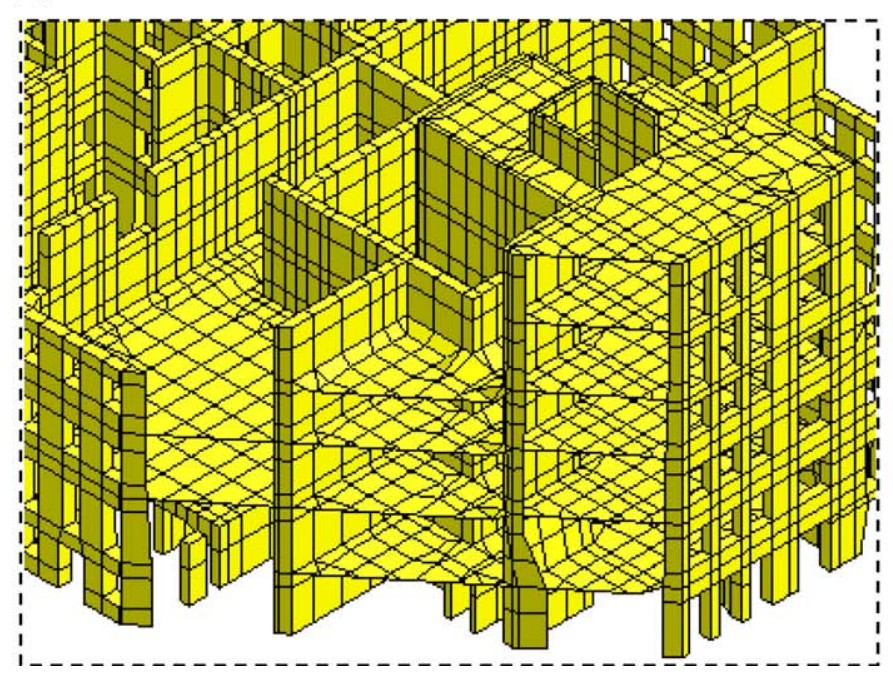

Fig. 5. Finite element mesh of the compound: (a) full mesh; and (b) detail.

deformed meshes. The maximum damage of the compound occurs in the buildings with more modifications in the structure, namely buildings A and D. Collapse of the buildings occurs due to out-of-plane failure of the external masonry walls due to the inexistent bracing system.

Through the non-linear seismic analysis, it was possible to verify that, in the full block model, the global safety factor SF is below the value of 1.5 required by the Portuguese code [16], see Fig. 9. The maximum load factor was approximately 0.7 and 0.9 for seismic action along the $x$ and $z$ directions, respectively. Collapse in the $x$ direction is governed by building $\mathrm{A}$ and collapse in the $z$ direction is governed by building D. It is also stressed that the responses are non-symmetric, as shown in Fig. 9. This is obvious because it is easier for the perimeter walls to overturn to the exterior (tension in the transverse backing walls) than to overturn to the interior (compression in the transverse backing walls).

From the analysis, it can be observed that the areas with additional reinforced concrete elements exhibit 


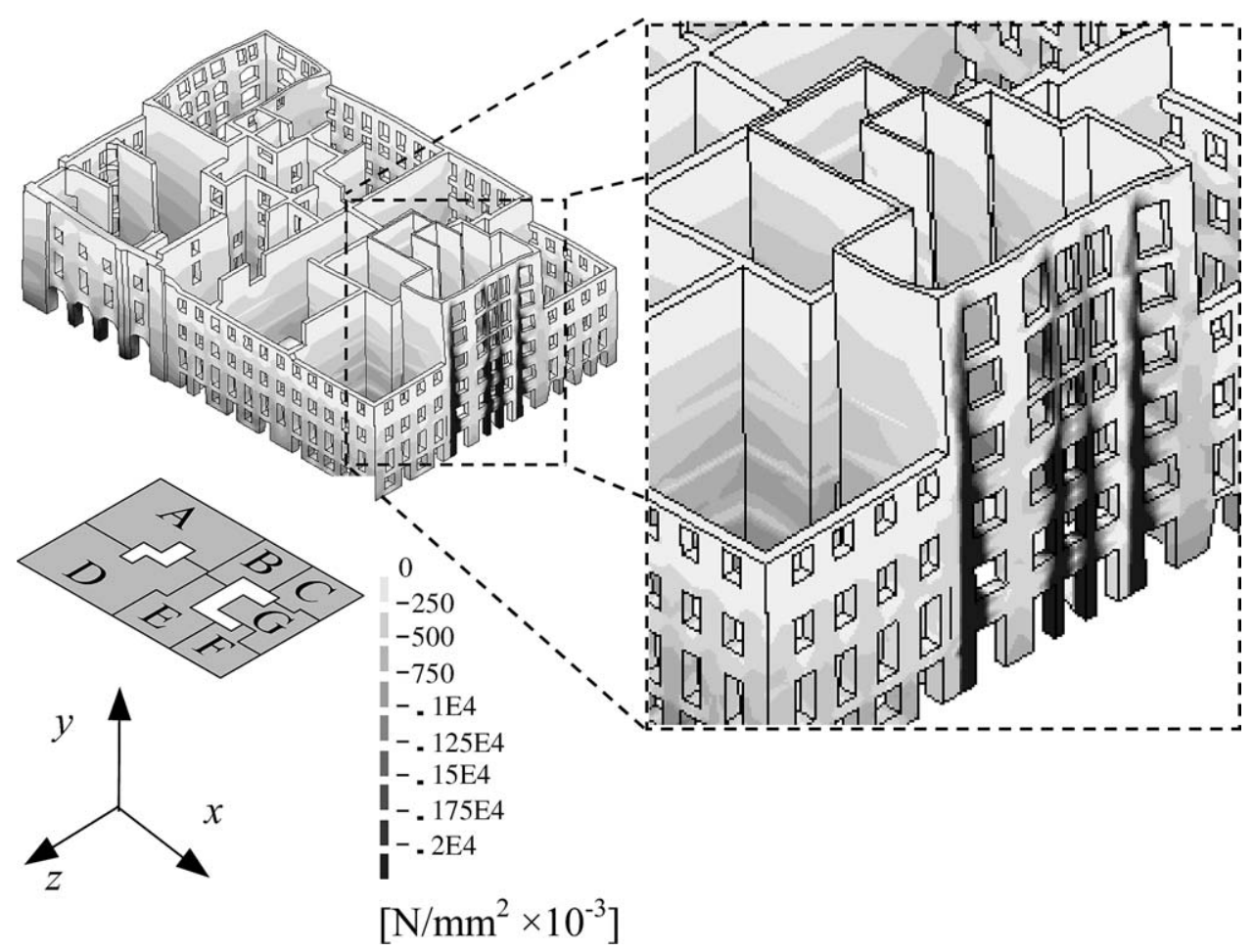

Fig. 6. Compressive stresses for vertical loading, in the complete block and in a detail of the reinforced concrete columns (values in $\left.\mathrm{N} / \mathrm{mm}^{2} \times 10^{-3}\right)$.

smaller displacements than areas with the response governed by the original structural elements. Such deformation behavior can result both in pounding damage or total collapse of the slabs, should the bond

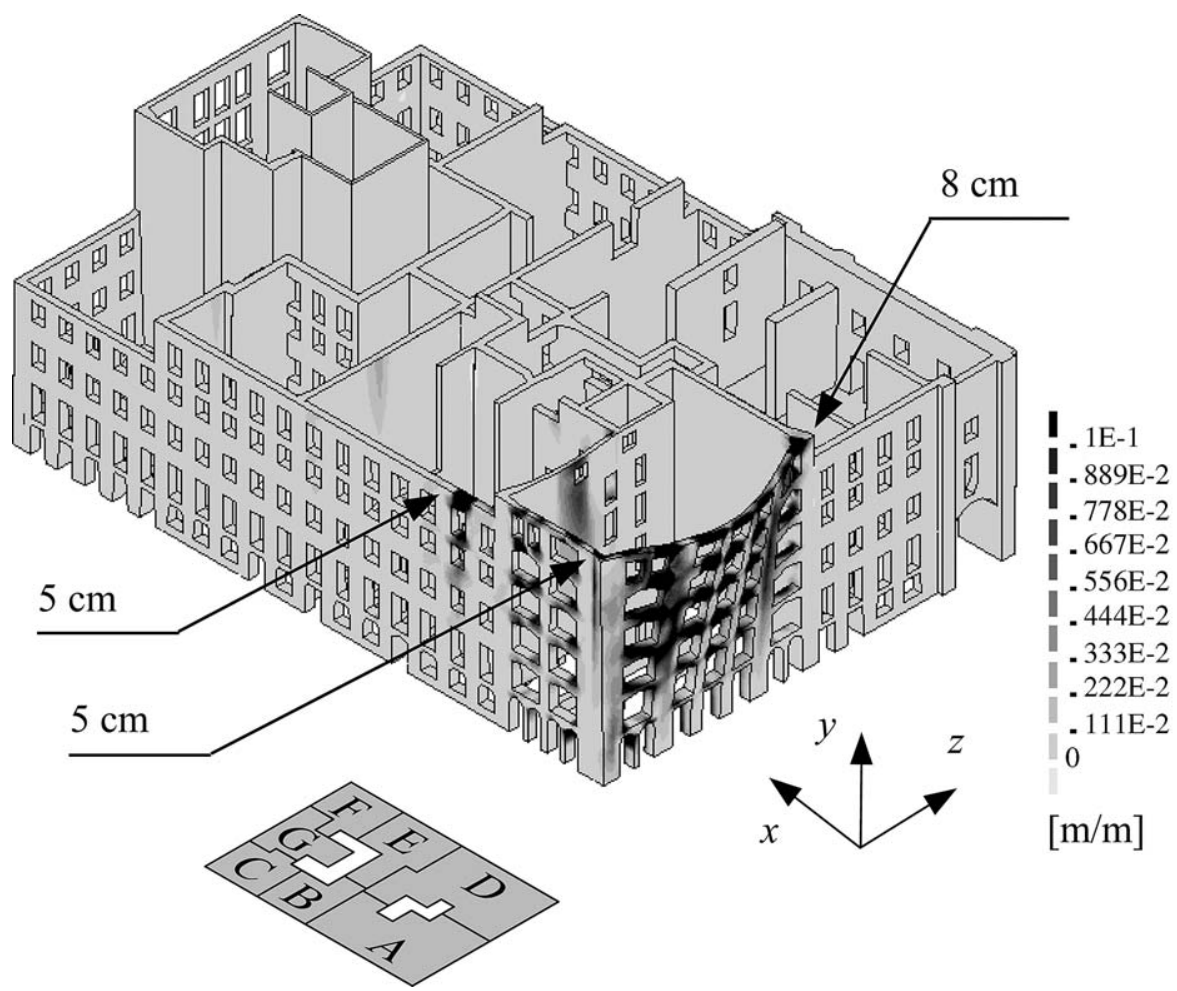

Fig. 7. Cracking pattern and deformed mesh in the full block for a horizontal seismic action in $-x$ axis (contour of maximum principal strains). 


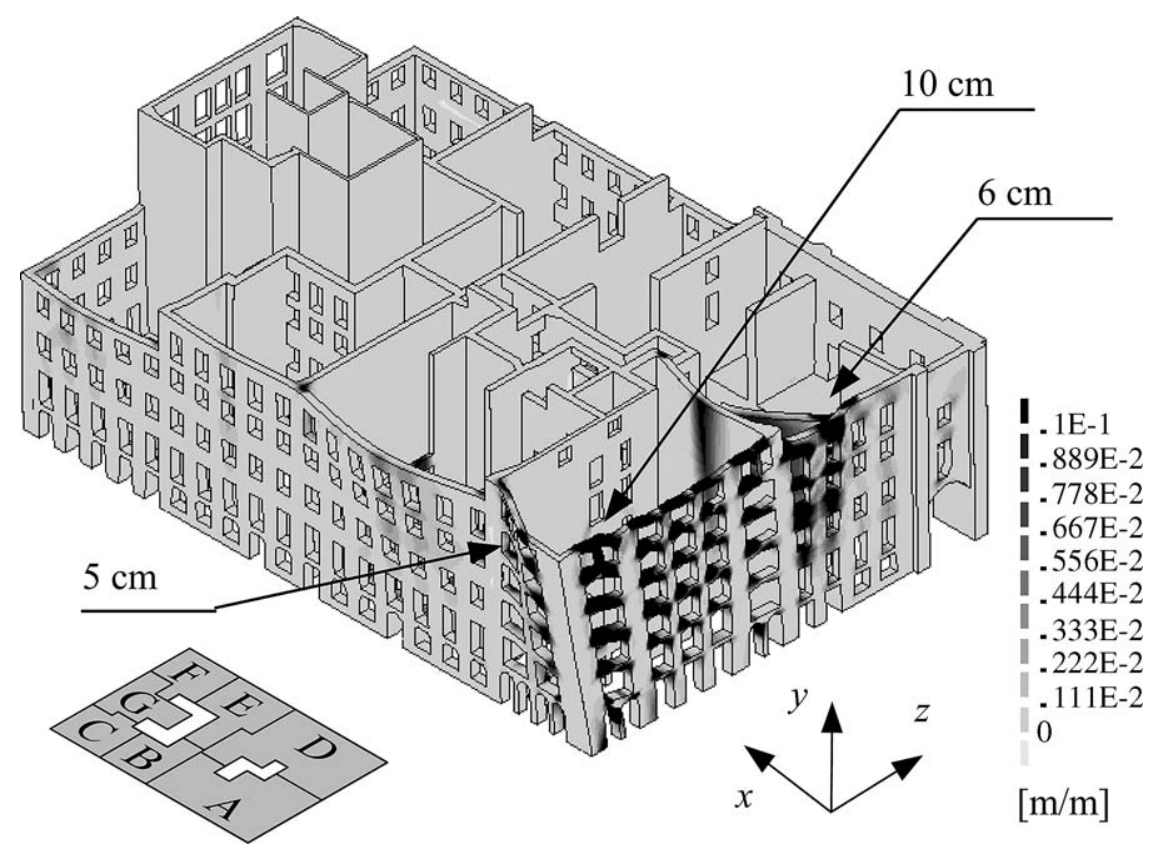

Fig. 8. Cracking pattern and deformed mesh in the full block for a horizontal seismic action in $-z$ axis (contour of maximum principal strains).

of the masonry walls be insufficient to resist the shear forces generated. As discussed earlier, the present model is unable to reproduce localized damage or other local phenomena.

In order to calculate the safety factors of the different buildings, a second model was prepared, including only the group of buildings with better seismic behavior. Fig. 10 shows the results of the new analysis for the seismic action along axes $x$ and $z$, in terms of deformed meshes and cracking patterns. In this analysis, it is possible to better observe the difference between the stiffness of the buildings with embedded structural elements in reinforced concrete and the buildings with stone masonry and timber floors. The difference in displacements is rather large, leading to premature detachment between the two types of buildings (see Fig. 10a).

A combination of the seismic analyses using the full and reduced block models allows to conclude that the zones more sensitive to seismic actions correspond to the buildings without rigid floors. Obviously, the analyses were carried out assuming that the connections between the floors and the masonry walls are not damaged during the seismic action, which is questionable. The conclusions are that: (a) either ties should be placed at each floor level, preferably with strengthening of the masonry piers between openings, or, if the resulting safety level is adequate, simply the roof level should work as a single tie (e.g. by using a ring beam or adequate timber logs); (b) stiffening of isolated buildings belonging to a building compound might lead to premature failure of the other (non-stiffened) buildings.

Highly intrusive structural modifications are not acceptable in agreement with modern conservation principles, and it seems advisable to tie historical buildings using either steel elements, placed horizontally, or using the timber floor beams, adequately connected to the masonry walls. This solution does not significantly stiffen the buildings, but prevents overturning mechanisms of the perimeter walls.

\subsection{Seismic vulnerability of the block}

From the two previous numerical analyses, it was possible to assess the seismic vulnerability of the different buildings of the compound. The obtained risk map distinguishes the most vulnerable buildings to seismic actions, which is a valuable guide for the public authorities regarding the decision of possible strengthening design and the priority level.

Fig. 11 shows the map of safety factors, where it can be observed that the corner part of building A gives the smallest safety factor, equal to 0.70 . Then, the rest of building A and building B have a safety factor of 0.90 , while building $\mathrm{D}$ has a safety factor of 1.15 . Building $\mathrm{C}$, with minor structural modifications with respect to the original conception, has a safety factor equal to 1.25. The zones with a higher safety factor are associated with buildings that suffered more intrusive modifications, namely, buildings E, F and G. 
(a)

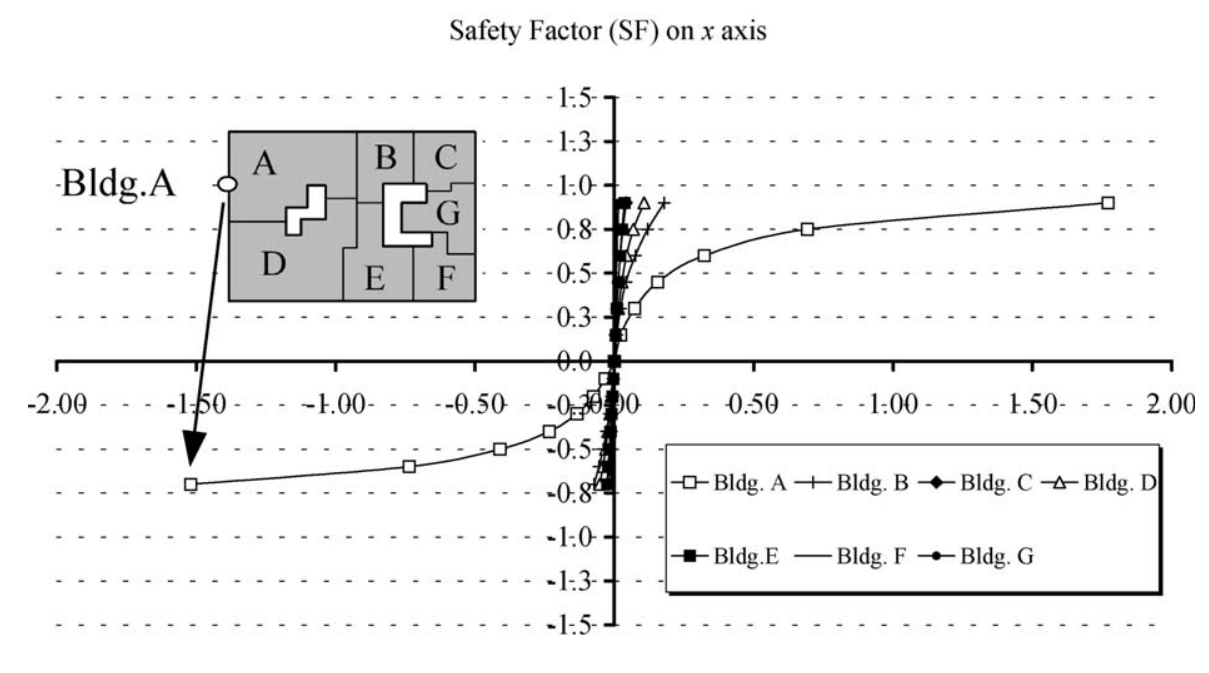

(b)

Safety Factor (SF) on $z$ axis

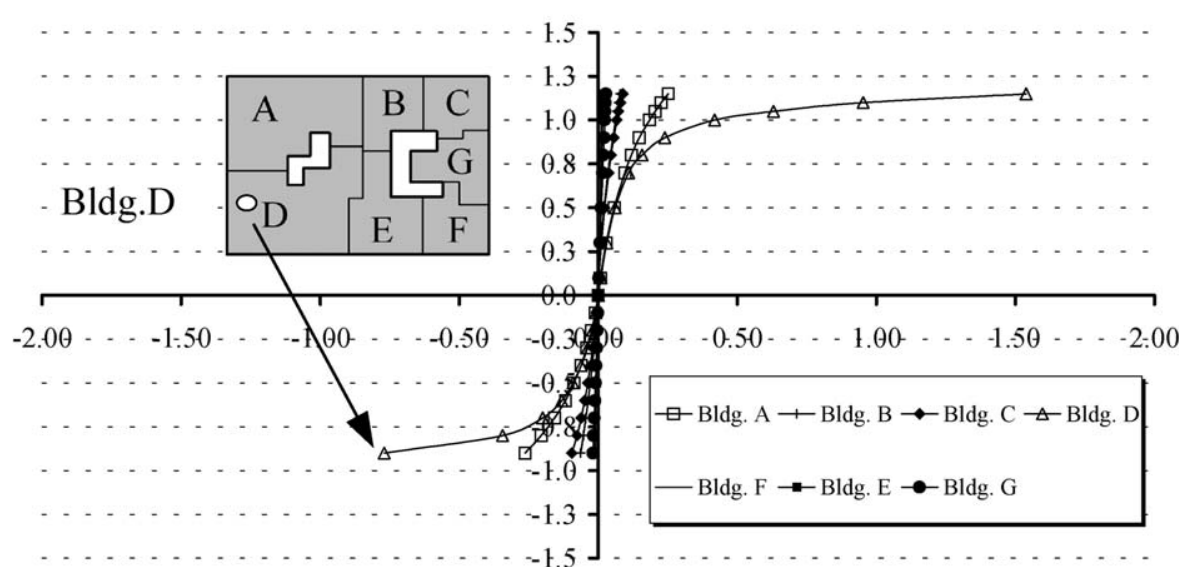

Fig. 9. Global behavior of the block, given by the diagram of safety factor SF vs. maximum horizontal displacement per building: (a) for seismic action along $x$ direction; and (b) for seismic action along $z$ direction.

\subsection{Discussion of the "block effect"}

A relevant issue in practical applications is the "block effect", i.e. the influence of the group of buildings in the seismic behavior of the individual buildings that compose the block. It is expected that the "block effect" may be felt, essentially, in two forms: (a) globally, the force distribution obtained from the individual analysis of each building will be different from the force distribution calculated when the entire block is taken into consideration; (b) locally, severe changes of stiffness in the buildings, resulting from the addition of reinforced concrete and steel members, will result in damage due to pounding effects and to the large stress peaks associated with a different deformation behavior.
In order to assess the global block effect, two additional analyses were carried out to study the behavior of two buildings separately. These are the building A, corresponding to a zone with larger structural damage and with a smaller safety factor, and the building $\mathrm{D}$, corresponding to a zone with structural configuration different from the traditional "Pombaline" construction, even if mostly original.

Fig. 12 illustrates the result of the analysis carried out with the isolated models, in terms of cracking patterns and deformed meshes. The individual buildings are more flexible than the compound and have lower safety factors. The seismic safety factors for both isolated models and the obtained load-displacement diagrams, seem to indicate that the "block effect" is 
(a)

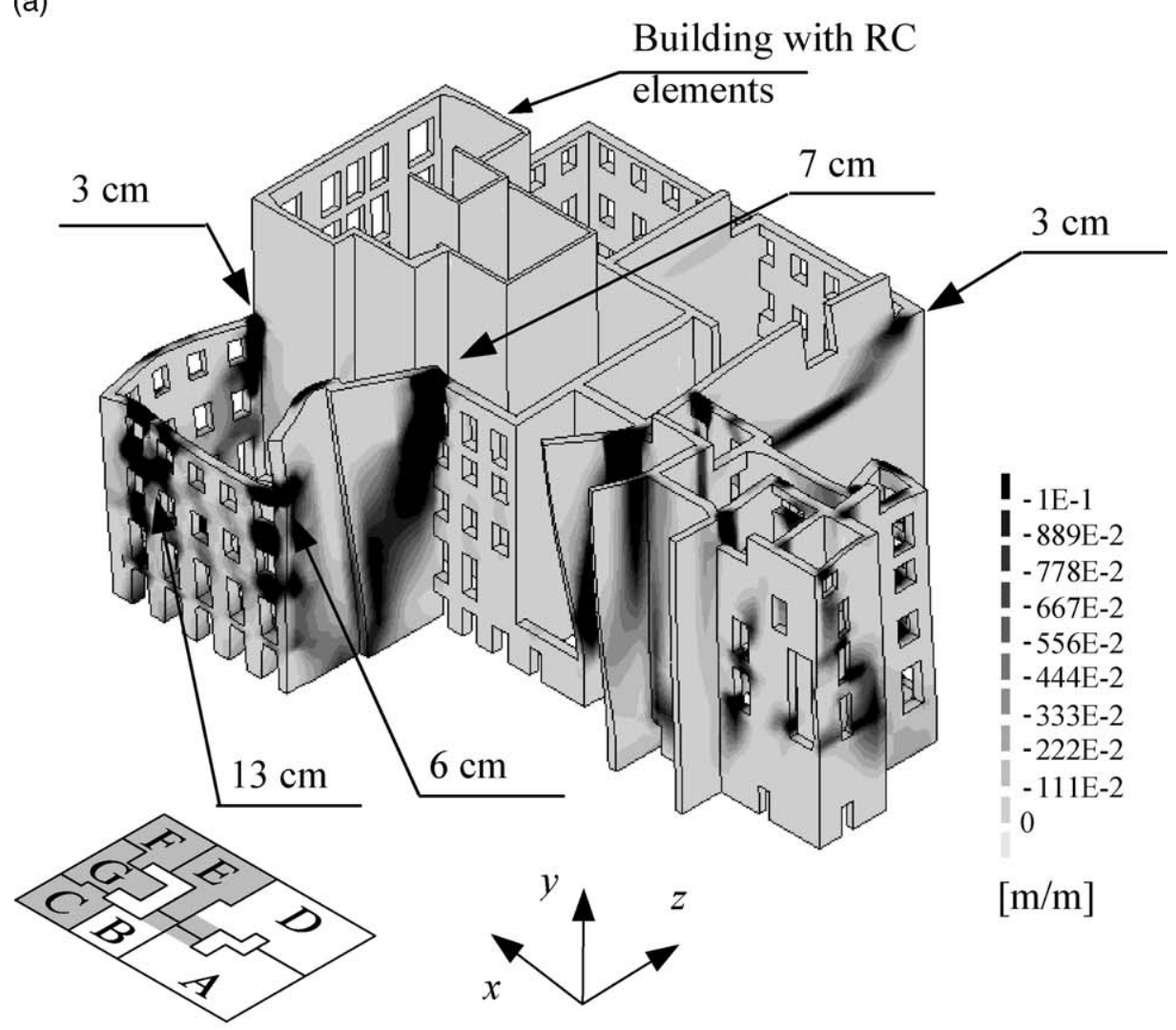

(b)

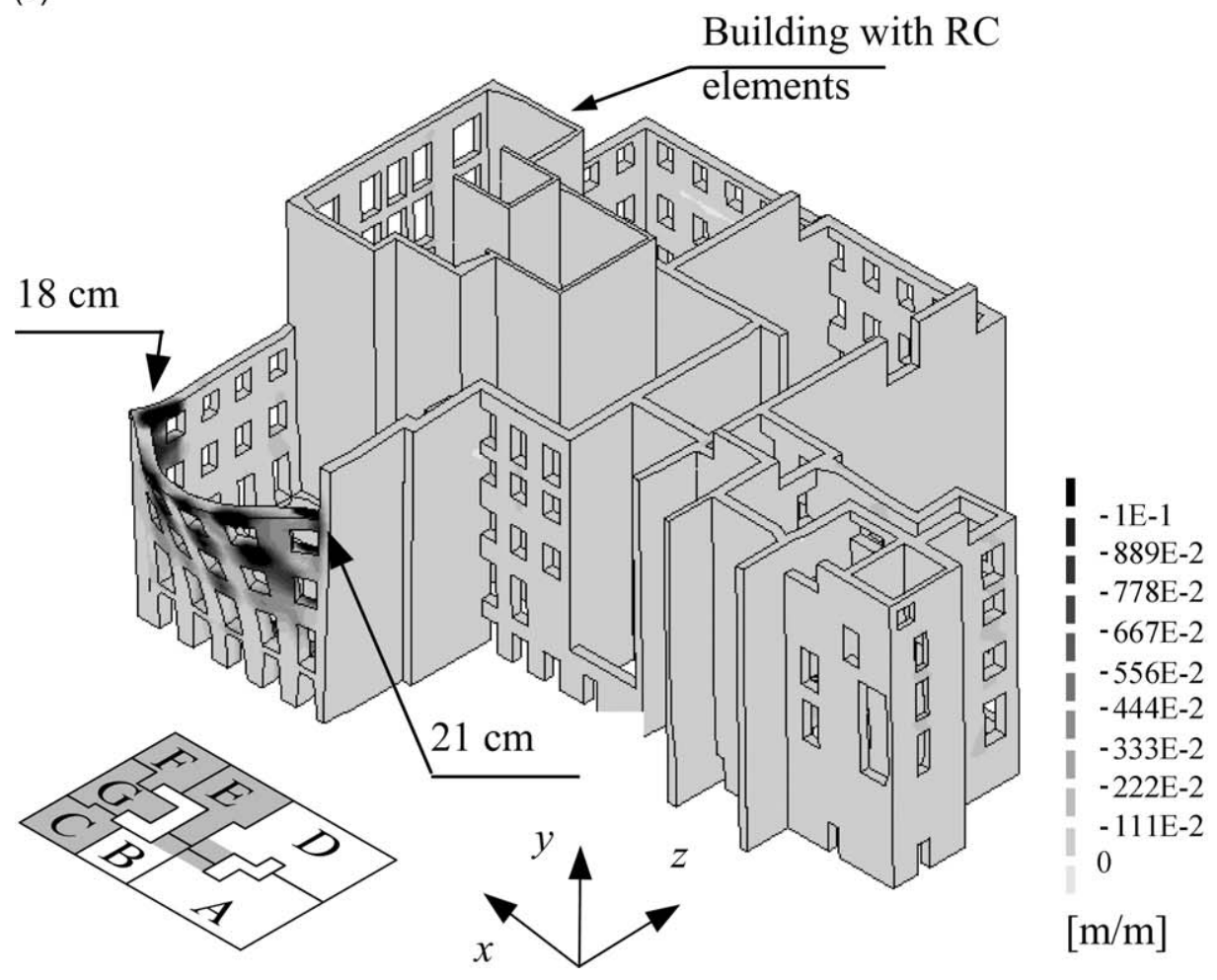

Fig. 10. Cracking pattern and deformed mesh in the reduced block: (a) for seismic action in the direction $+x$; and (b) for seismic action in the direction $-z$. 


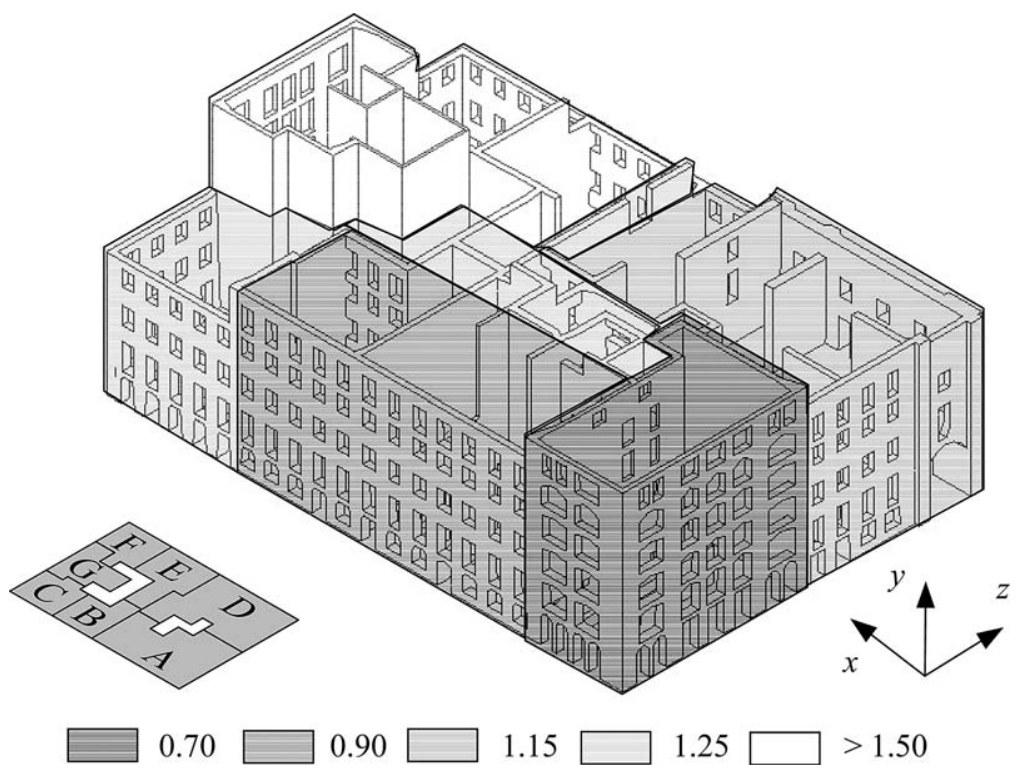

Fig. 11. Seismic vulnerability map of the block, given by the calculated safety factors.

beneficial for the buildings, as can observed in Table 1 . This means that safety analysis of historical buildings belonging to larger compounds can be carried out with isolated buildings, which reduces the effort and time to great extent. Nevertheless, it must be stressed that the difference in the results are rather large and, if the isolated building analysis indicates a unsafe condition, it may be suitable and economically justifiable to refine the analysis using the full compound.

\section{Proposed methodology}

Based on the above, a simple methodology is proposed next, with the objective to deal systematically with the issue of substantial structural alterations in the blocks of historical city centers in seismic areas. Such methodology consists of the following steps to be carried out along a reasonable time span by the local/ national authorities:

- Carry out a geometrical survey and identification of the urban compound;

- For each of the blocks of buildings, perform a survey of the existing structure, a characterization of the structural materials and a classification in categories of existing structural changes. The following criteria to classify the modifications are suggested: (a) buildings with significant modifications-structural changes in more than $50 \%$ of the original volume of the building, with or without extra floors; (b) buildings with moderate modifications - structural changes between $20 \%$ and $50 \%$ of the original volume, with a maximum of one extra floor; (c) build- ings with minor modifications - structural changes in less than $20 \%$ of the original volume, without extra floors;

- For each block, construct a finite element model and perform the analysis, determining the shear forces in the structural elements and the seismic vulnerability of the buildings. With this information, set up a plan and schedule with the definition of priorities for retrofitting. If the owner does not carry out the retrofit according to the schedule, the municipality takes over this task and claims the costs from the owner;

- Finally, the survey and structural model of the complete block should be provided to the owners. Any construction works in a building should only be approved if it is demonstrated by the owner that the works do not have a negative contribution to the safety of the block.

The last years witnessed large developments in survey and characterization tools. A comprehensive set of tests, devices and techniques, mostly non-destructive or low invasive, are available, enabling the gathering of the data required to construct and validate structural models. These methods are of interest not only before the actual works in the construction but also during and after the works, as modeling of the structure is only one specific phase of the overall process.

The preparation, modeling and analysis of historical buildings can be extremely complex and time consuming. The diversity of the structural schemes together with the use of different materials, results in the need to adopt simplified numerical models of the constructions, in order to make the analysis feasible. The obvious dif- 
(a)

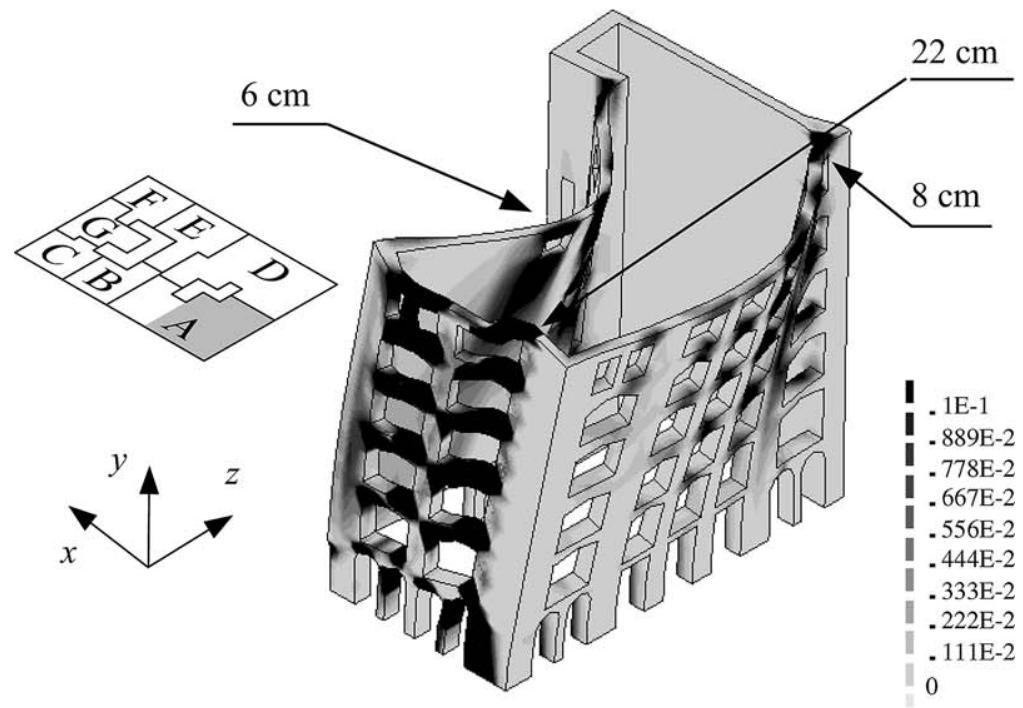

$[\mathrm{m} / \mathrm{m}]$

(b)

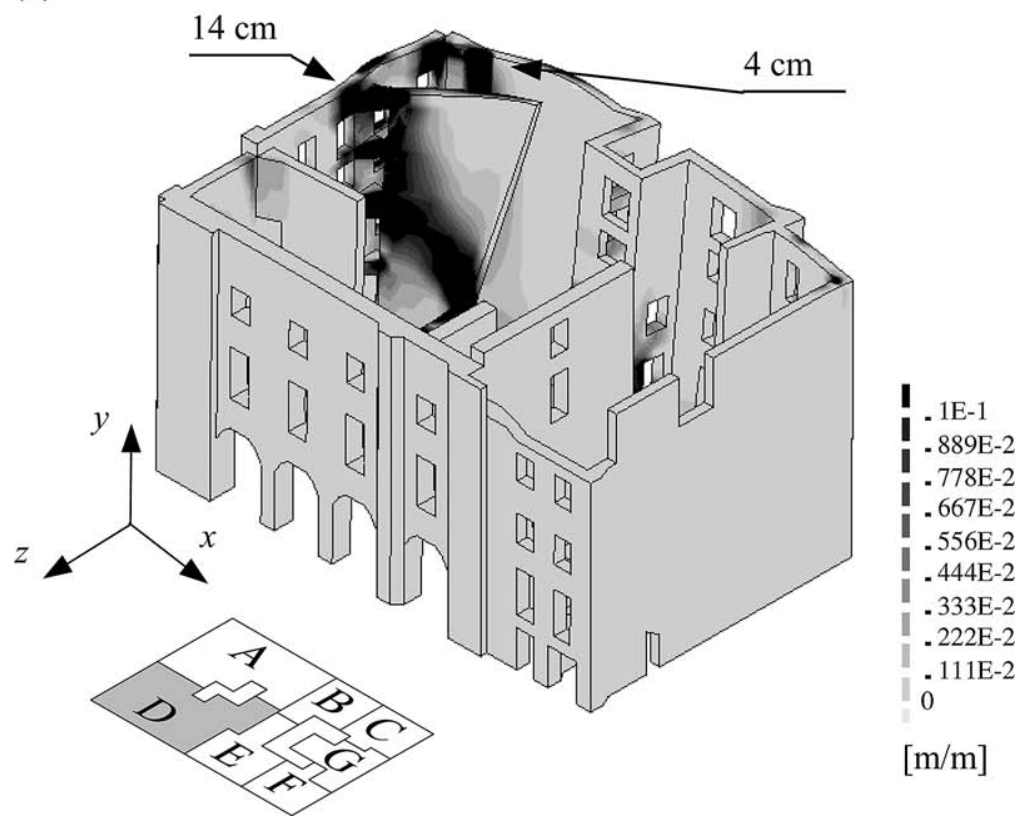

Fig. 12. Cracking pattern and deformed mesh in the isolated models (a) for building A (seismic action $-x$ ); and (b) for building D (seismic action $-z)$.

ficulty is the trade-off between the ability of the model to accurately represent the structural behavior of the construction and the level of simplification (and inherent costs).

Table 1

Safety factors (SF) of the buildings A and D

\begin{tabular}{|c|c|c|c|c|c|c|}
\hline \multirow[t]{2}{*}{ Building } & \multicolumn{3}{|c|}{ Isolated model } & \multicolumn{3}{|c|}{ Full model } \\
\hline & $\mathrm{SF}_{x}$ & $\mathrm{SF}_{z}$ & $\mathrm{SF}$ & $\mathrm{SF}_{x}$ & $\mathrm{SF}_{z}$ & $\mathrm{SF}$ \\
\hline A & 0.50 & 0.75 & 0.50 & 0.70 & $\geq 0.90$ & 0.70 \\
\hline $\mathrm{D}$ & 0.65 & 0.95 & 0.65 & $\geq 0.70$ & 0.90 & 0.90 \\
\hline
\end{tabular}


Table 2

Costs involved in survey and characterization and modeling $\left(10^{3} €\right)$

\begin{tabular}{llll}
\hline Task & Cost per building & Cost per block & Total \\
\hline Architectural survey & 10 & 70 & 4200 \\
$\begin{array}{l}\text { Structural survey } \\
\text { Materials }\end{array}$ & 9 & 63 & 3780 \\
characterization & & & 250 \\
$\begin{array}{l}\text { Foundation survey } \\
\text { Geotechnical survey }\end{array}$ & 2 & 14 & 840 \\
$\begin{array}{l}\text { Modeling } \\
\text { Total }\end{array}$ & & 400 \\
\hline \multicolumn{1}{c}{ a Overall survey and sampling. } & & 1800 \\
b Using sampling and existing data. & & 11270 \\
\hline
\end{tabular}

It is not realistic to use detailed models of walls and connections in large scale analysis, not only because the geometric and material properties of the constituents are difficult to characterize but also due to the time/economy constraints. For most large-scale analyses, it is acceptable to model both regular masonry and rubble masonry walls assuming a continuum homogeneous material.

From the experience gained in the work described here, the cost estimate of Table 2 can be made for setting up a priority plan in Lisbon. This estimate seems quite reasonable compared to the municipality annual budget and the fact that the estimated costs are to be spread over a number of years. The amount per building, around $27000 €$, seems quite reasonable as well, taking into account the high real estate prices in the area, not to mention its importance as architectural heritage. Nevertheless, this value must be considered in the specific economical context of each historical center and local conditions.

\section{Conclusions}

The structural system implemented in the downtown buildings in Lisbon was innovative for the period of reconstruction. After the Lisbon earthquake of 1755, the issues related to the safety of the buildings were extensively studied and, as a result, a system of composite timber-masonry structural elements was developed for the buildings, aiming at providing adequate strength and energy dissipation with respect to seismic actions. Through time, successive occasional structural modifications introduced weaknesses in the structural system, decreasing the resistance of the buildings to seismic actions. The structural modifications have been made with a clear absence of a policy for global analysis and introducing materials with mechanical characteristics non-compatible with the original materials.

The finite element analyses carried out confirmed the observed failure mechanisms of ancient masonry build- ings due to seismic actions: overturning of the perimeter walls. In cases where safety against seismic actions is clearly insufficient, owners and regulators must address the issue of retrofitting these structures. As preventive measures, it seems advisable to tie the buildings with steel rods or to strengthen the timber floors, especially taking into account the connections with the masonry walls.

From the modeling and analysis point of view, the following aspects should be stressed: (a) the complexity of ancient buildings requires that simplified models of the structures are considered. In the case of timber structures, special attention must be devoted to the deterioration of wood and connections. Here, the timber floors and backing structures have been neglected and it must be ascertain if this hypothesis is not overly conservative (heavy structural modifications can hardly be accepted from the conservation point of view and modern safety codes are not directly applicable to ancient constructions); (b) if internal light "walls" are present (thickness of $0.20-0.30 \mathrm{~m}$ ), they can be neglected for the purpose of seismic analysis, because their contribution is marginal; (c) ancient buildings in historical city centers usually belong to a block of buildings mutually connected but, for the purpose of analysis, it is conservative to consider each building individually (care must be taken for the analysis not being over-conservative).

Finally, a methodology to define the approach towards works in historical city centers in seismic areas is defined, including survey, analysis and definition of priorities of action. The cost of the proposed approach is also addressed.

\section{References}

[1] Carocci CF. Guidelines for the safety and preservation of historical centers in seismic areas. Proceedings Historical Constructions 2001, Guimarães, Portugal. 2001, p. 145-65.

[2] Giuffrè A. Seismic damage in historic town centers and attenuation criteria. Ann Geofis 1995;38(5-6):837-43.

[3] Giuffrè A, editor. Safety and conservation of historical centers: the Ortigia case. Roma, Bari: Editori Laterza; 1993 [in Italian].

[4] D'Ayala A, Speranza E. Definition of collapse mechanisms and seismic vulnerability of historic masonry buildings. Earthquake Spectra 2003;19(3):479-509.

[5] Augusti G, Ciampoli M, Giovenale P. Seismic vulnerability of monumental buildings. Struct Saf 2001;23(3):253-74.

[6] Giuffrè A, Carocci C, editors. Code of practice for the safety and the conservation of the historical centers of Palermo. Bari: Editori Laterza; 1999 [in Italian].

[7] Binda L, Penazzi D, Valuzzi MR, Cardani G, Baronio G, Modena C. Behavior of historic masonry buildings in seismic areas: lessons learned from the Umbria-Marche earthquake. Proceedings of the 12th International Brick/Block Masonry Conference, Madrid, Spain. 2000, p. 217-35.

[8] Nunes J, Ramalhete C, Ramalhete D, Senos ML. Seismicity between Terreiro do Paço and Sacavém, in the river area of 
Lisbon. Proceedings of the Second National Meeting of Seismology and Earthquake Engineering, Porto, Portugal. 1994, p. I [in Portuguese].

[9] Barucci C. Anti-seismic constructive techniques in the historical buildings of meridian Calabria. Roma: ARCO-Manutenzione e Recupero Nella Città Storica; 1993.

[10] Ramos LF. Experimental and numerical analysis of historical masonry structures. M.Sc. Thesis. University of Minho, 2002 [in Portuguese, also available from www.civil.uminho.pt/ masonry].

[11] Croci G. The conservation and structural restoration of architectural heritage. Southampton: WIT Press; 1998.

[12] TNO. Diana 7.2, user's manual. The Netherlands: TNO Building and Construction Research; 1999. Available from www.diana.tno.nl.
[13] CEN. Eurocode 8, design provisions for earthquake resistance of structures. Brussels: CEN; 1995.

[14] Lourenço PB. Computations of historical masonry constructions. Prog Struct Eng Mater 2002;4(3):301-19.

[15] Meli R. Structural engineering of historical buildings. Mexico City: Fundación ICA; 1998 [in Spanish].

[16] INCM. Portuguese safety and actions code. Diário da República, Lisboa, 1983 [in Portuguese].

[17] Rots JG. Computational modeling of concrete fracture. Ph.D Thesis. Delft University of Technology, the Netherlands, 1988.

[18] Alfano G, Rosati L, Valoroso N. A numerical strategy for finite element analysis of no-tension materials. I J Numer Methods Eng 2000;48(3):317-50.

[19] Lourenço PB. Anisotropic softening model for masonry plates and shells. J Struct Eng ASCE 2000;126(9):1008-16. 